\title{
Building High Quality Products by APPlying QUALITY MANAGEMENT ACTIVITIES ON SDLC
}

\author{
Lena Khaled \\ Department of Software Engineering, Zarqa University, Amman, Jordnan
}

\begin{abstract}
The main concept of this paper is the term quality. The main part of building any software product is reaching a high level of quality and developing the quality it reaches. This paper concentrates on applying activities of quality management on the software process (the life cycle of building the software) to achieve high level of quality. These activities are: planning, control and assurance. By the term quality we mean the characteristic of the software after we build it; it must be high and according to customer's requirement.
\end{abstract}

\section{KEYWORDS}

Quality, software development process, quality management activities \& quality documentation.

\section{INTRODUCTION}

The quality of software system is one of the most common things that are discussed with software engineers. According to IEEE, software quality is the degree to the system that meets the customer's requirements and expectations. There has always been an adjustment between high quality and timeto-market, but choosing the right life cycle to build the software always drives high quality to the product. Life Cycle Quality Management, (LQM), helps to provide high quality throughout the entire software development life cycle by reducing costs, risks and defects [1][6]. Skilled people, optimal processes, and an effective technology in each phase of the process are always combined. Poor quality affects on time to market and also it affects on cost because software sometimes needs to re design to meet original requirement [2] [8].If the defects occur in the development life cycle at the first stage and not detected earlier then it will be more cost to repair [3] [4].Software Quality Method (SQM) always focuses on customer requirements. Each product has a unique technical and customers needs, therefore SQM always evaluates the appropriate tools and methods to tailor them for each product $[5][7]$.

This paper introduces how quality management activities influence the life cycle (process) of any software to produce a high quality product, and is organized as follows:

Section 2(Related works): this section includes and introduces papers that have any related topics to this work; it shows all the works that introduce the quality as a main part of building the software product. Section 3 defines the software development life cycle of the product and the basic stages of it; it shows the basic definition of the software process and the types of it. Section 4 defines the basic activities of quality management; it introduces the basic definitions of each activity: planning, control and assurance. Sections 5 and 6 define the result and conclusion consecutively.

\section{RELATED WORKS}

Many papers discuss quality as a basic goal through building the software. [9], this paper works on quality by adopting the component based approach in software product line. The aim of this paper is to increase the quality of the product by choosing the specific components for example increasing 
International Journal of Engineering Sciences \& Emerging Technologies, Feb 2012. ISSN: 2231 - 6604 doi: 10.7323/ijeset/v1_i2_11 Volume 1, Issue 2, pp: 90-96 OIJESET

flexibility, reliability and usability. [10], this work describes how quality attributes affect building the architectural design by building the architectural decisions which derived from these quality attributes. Humphrey [11] discusses in his work the major problems of the software community are caused as a result of not using data when measuring the quality of any product. Then he mentions that the basic measures for any quality are time, size and defects. [12] Discusses that any task that is changed, installed or modified needs the quality assurance activity to verify it. Jasmine and Vasantha [13] introduce the quality, application and product of the system by proposing a quality metric (Defect Removal Efficiency, DRE) that provides benefits for the project and process level. [14], this paper discusses the relation between code readability and its relation with software quality, this relation correlates strongly with traditional measures of software quality, code changes and defect reports.

This work is described how quality management activities applied on software life cycle to build high quality products.

\section{Software Development Life Cycle (Software Development PROCESS)}

A software process is a set of consequent steps to achieve a specific purpose. With development software process the purpose is to satisfy the needs of the user or client. The main goal of the process is to build the software product with a low cost, low cycle time and a high level of quality. Achieving a high level of quality needs an optimum process, so several process models were proposed [15][21][29].

A process model can be defined as a plan of the development process. A process model has two distinct uses [16] [22].

- It is used as the basis plan of a project

- It is used as the analysis description of what really happens during building the project.

The typical activities of any process model are [23][24]:

- System requirement and analysis

- Architectural design

- Design details

- Implementation

- Unit development

- Software integration and testing

- System integration and testing

- Installation at site

- Site testing and acceptance

- Training and documentation

- maintenance

A business process is a set of activities designed to produce a product result for a customer or a market, in general business process categorised into three major concepts: Documentation, Redesign, and Execution.[18] [19][20].

Several process models can be used: Waterfall, prototyping, incremental, agile and open source. Each process model follows a particular life cycle to guarantee success in the process of software development [17] [28][41]. 


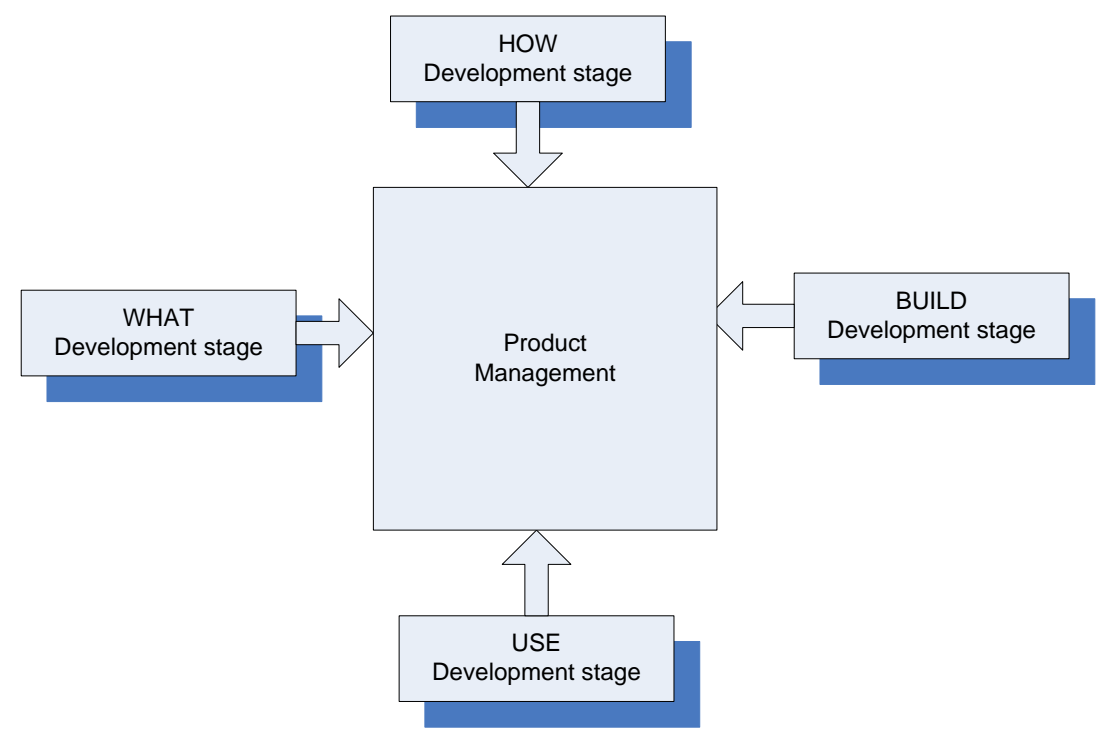

Figure 1. Software Development Life Cycle Stages

Figure 1 illustrates that software development life cycle has four generic stages. These stages symbolize the main activities of the development process such as [26][27][25]:

WHAT: illustrate WHAT the software does.

HOW : illustrate $H O W$ the software does WHAT.

BUILD: improve or BUILD the code to perform the WHAT.

$\boldsymbol{U S E}$ : deploy the code or $\boldsymbol{U S E}$ the computer code built previously.

\section{Quality Management Activities}

The quality management activities checks the deliverable product if it is being built according to organisational standards and goal. Quality management is very important for the success of building any software product. Quality management activities can bedivided into [30] [31]:

- Quality planning

- Quality control

- Quality assurance

The organization of the quality management activities is important for the team that is developing the large and complex system. Quality documentation is an important way to organise these activities; [30] [32] the quality documentation is a record of what has been done by each group worked on the project. Correct, complete, consistent and unambiguous information in the quality documentation always meet customers' requirements [30][32][33].

\subsection{Quality planning}

It is the first step in the quality management activities and is defined as a process of developing a quality plan for a project. The quality plan should specify the desired qualities and describes how these qualities can be achieved; the quality plan should also select the standards of the organization that are appropriate to a specific product and development process. The good quality planning is to assist communication with every one in the project, to ensure that all steps are corrected, completed and on time. [30][34][35].

\subsection{Quality control}

Quality control checks the software development process to make sure that the quality assurance standards are being followed. Quality reviews is the mostly used method to validate the quality of the process or the product [30] [36] [37]. 
International Journal of Engineering Sciences \& Emerging Technologies, Feb 2012. ISSN: 2231 - 6604 doi: 10.7323/ijeset/v1_i2_11 Volume 1, Issue 2, pp: 90-96 OIJESET

\subsection{Quality assurance}

It is a set of processes of selecting the standards that should be applied to software development process. The goal of software quality assurance is to improve quality by monitoring development process to ensure the applicable of the standards and the procedures [39] [40]. One part of these processes is selecting the tools and methods to support those standards. The important issue in software quality assurance activity is that testing the functions of the application per the test plan and then recording all defects [43]. Two types of standards are defined below [30]:

Product standards: these are standards that are applied to the software product which includes documentation and coding standards [45].

Process standards: these are standards that define the process that should be followed during the development of the process.

Over the years a number of quality frameworks have been developed to improve their products which offering to customers [37].

\section{THE RESULT}

The basic thing of quality mangment activities is that the qualities of development process directly influences the quality of the delivered product, so choosing the optimal process model is the basic and first part of builing any software.

Figure 2 illustrates the effects of choosing the process model on quality; it shows that the first part is choosing the process model then building the product. After that the quality of the product is checked to make sure that the delivered product is with a high level of quality.

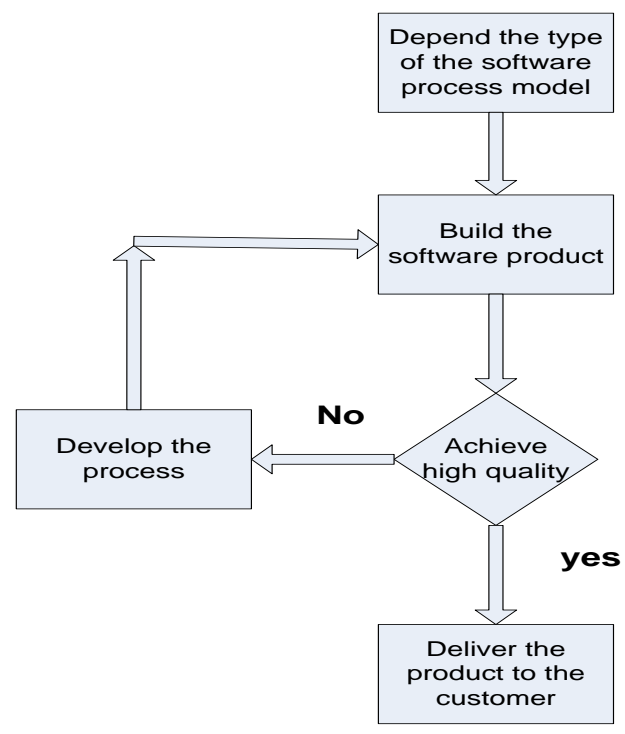

Figure 2. Process model and quality

It must be known that software quality is a very difficult concept; it is sometimes not known how to identify certain quality characteristics, therefore the quality must applied and checked on software product starting from preparing the specification of the product through the life cycle that builds it, and finally delivering the product with high level of quality. Figure 3 illustrates that. 


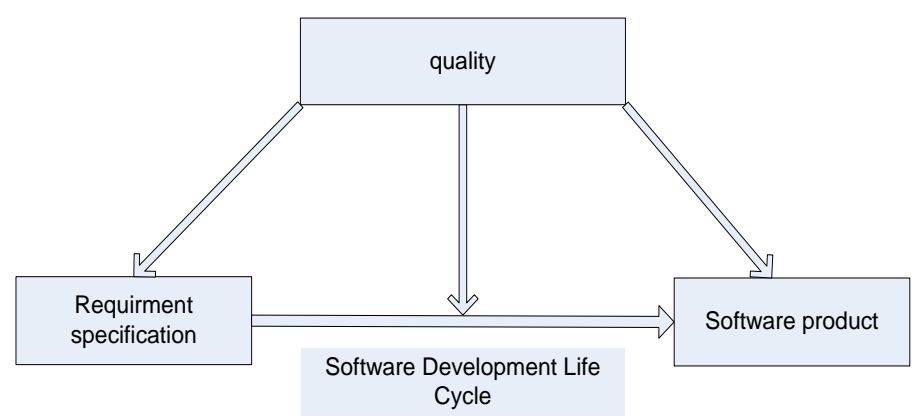

Figure 3. The quality and the product

Any new requirements specifications or changing on the requirements must enter the life cycle of quality mangment activities. It makes sure that quality is taken into account from the beginning. Figure4 shows that.

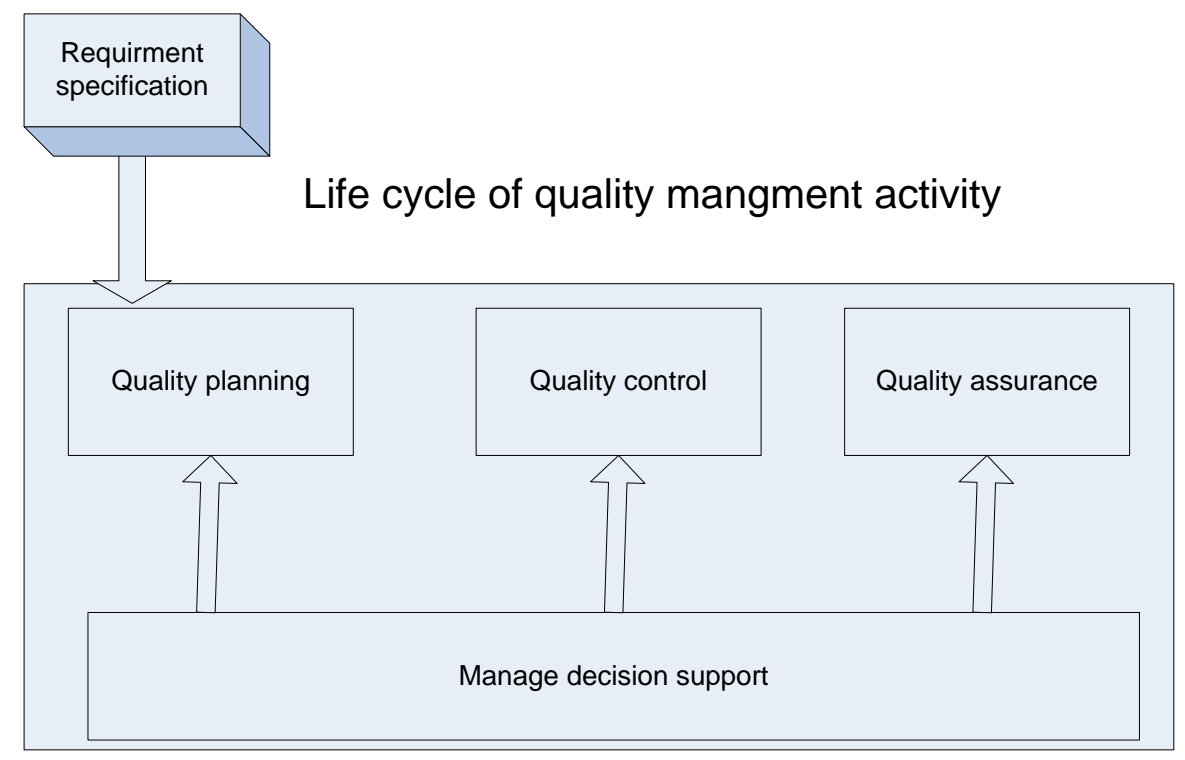

Figure 4. New requirement and quality management activities

In this section the theory of achieving high quality when building any product is discussed. However, there are some important reasons why data is not used in it. these reasons include:

- There is no specific definition for quality measure

- the data are not easy to gather

Software engineering is basically a team activity in which members are assigned responsibilities based on their roles in the team, selecting the best people for these roles based on their personalities and this is the main factor for building an effective team [44]. Also it must be known that the team of quality management should be independent from the development team, so that they can take an objective view of the software product. Also the incorrect choice of life cycle causes lower quality of product and wasted efforts among members of project team [38][42][43]

\section{CONCLUSION}

The product's quality is the main goal to every business product. This survey focuses on both Quality Management Activities and software lifecycle. It shows how the activities of the Quality Management are applied on the life cycle of a product in order to build it with a high quality. It also shows how choosing the optimal process model for building process reduces time, risk, cost and mainly producing the product with high level of quality. 


\section{REFERENCES}

[1] Borland the open company,(2007), "Driving Quality throughout the software Delivery Lifecycle", white paper.

[2] Barbacci M, (2003),"Software Quality Attributes \&Architecture Tradeoffs" Software Engineering Institute, Carnage Mellon University.

[3] Boehm B,(1978),"Characteristics of Software Quality", North Holland.

[4] Walts H,(1995),"A discipline of Software Engineering", Addison Wesley.

[5] Hoffman D,(2011),"Software Quality Methods", Software Quality Methods, LLC.

[6] Claruss consulting Group,(2010)"Softwre Quality Attributes :following the steps".

[7] Boegh J,Depanfilis S,Kitchenhan B,Pasquini A,(1999),"A method for Software Quality lanning,Control,and Evaluation",IEEE Software.

[8] Jones C,(1995),"Pattern of larage Software Systems:Faliure and Success".

[9] Khaled L, (2011),"Integrating Components in Software Product Line to Build High Quality Products", Journal of Computer Science, Volume, Issue 8, PP: 1167-1171.

[10] Bachman F, Bass L, Klein M, "Moving From Quality Attribute Requirement to Architectural design , "Software Engineering Institute, USA.

[11] Humphrey W,(2009),"The Software Quality Profile", Software Engineering Institute, Carnage Mellon.

[12] Scarpino J, (2008),"Quality in SDLC", University of Pittsburgh.

[13] Jasmine K, Vasantha R,(2007),"A Quality Metric For Components Based Softwre Products, World Academy Of Science ,Engineering \& technology

[14] Buse R, Weimer W,(2008),"A Metric for Software Readability",ACM.

[15] Jalote P,(2008),"A concise Introduction to Software Engineering" Springer ,ISBN:978-1-84800-301-9.

[16] Bell D,(2005),"Software Engineering for student", Fourth edition, Addison-Wesley, ISBN-10:0-32126127-5.

[17] Davis A ,Bersoff E, Comer E,(1988),"A strategy For Comparing Alternative Software Development Life Cycle Models",IEEE Transactions on Software Engineering VOl. 14,NO.10.

[18] SPARX systems UML tutorial,(2004),"The Business Process Model'.

[19] White S,(1999),"Process Modelling Notations \&Workflow Patterns", IBM Corp., United States.

[20] Web Sphere Software Technical Sales, IBM,(2007),"Why Model business process?'.

[21] Barn B, (2007),"Business Process Model ",e-Framework Workshop ,Thames Valley Univwersity.

[22] A survey of System Development Process Models,(1998). www.ctg.albany.edu.

[23] Toth K,(1997),"Software Engineering Best Practices",A lecture notes.

[24] Ludewig J,(2003),"Models in Software Engineering-an introduction", Institute of Software Technology, Germany.DOI:10.1007/s/1027-003-0020-3.

[25] Designing and Managing a Software Project.www.desigingprojectmangment.com.

[26] Donaldson S, Siegel S,(2000)," Successful Software Development", second edition, Prentice Hall,ISBN:013-0868826-4.

[27] Buyya R, "Software Life Cycle \& Models", www.buyya.com.

[28] Boehm B,"A spiral Model of Software Development \&Enhancement", www.dimap.ufrn.br/ jair/ES/artigos/SpiralModelBoehm.pdf

[29] Gossain S,,(2003),"Using the Shlaer-Mellor Method to support a level 4 Software Process", published in Software Engineering Notes, ACM Press.

[30] Somerville I,( 2007)," Software Engineering", Pearson education, eighth edition. ISBN: 10:0-321-313798.

[31] Catarino M,(2009),"Software projects' most important activities of Quality Management :A Delphi Study", communications of the IBIMA,VLO 11, ISSN: 1943-7765.

[32] Good documentation \& quality management principles , managed by World Health Organization(WHO). http:// apps.who.int/

[33] A documentation Guide,(2010),"Guidelines for developing Quality Documentation ",International Seed Testing Association(ISTA).http://www.seedtest.org.

[34] Thisse L, (1998),"Advance Quality Planning: A guide For any organization", Quality Progress. http://texas-quality.org

[35] Developing a Quality Plan ,(2011), www.thecqi.org/worldqualityday.

[36] Louisiana Department of transportation and Development,(2008),"Construction Plan Quality Control /Quality Assurance manual. www.dotd.la.gov.

[37] Manus J,(2007),"Software Engineering :A quality Management Perspective", The TQM magazine, VOL 19,No.4, pp:315-327.

[38] Hoffman D, (1993),"The role of the quality group in Software Development". 
International Journal of Engineering Sciences \& Emerging Technologies, Feb 2012. ISSN: 2231 - 6604 doi: 10.7323/ijeset/v1_i2_11 Volume 1, Issue 2, pp: 90-96 CIJESET

[39] Eldrandaly Kh,(2008),"A knowledge -based Advisory System for Software Quality Assurance", International Arab Journal of Information Technology VOL. 5 ,NO.3.

[40] Windley Ph,(2002),"The Discipline of Product Management ", www.Windley.com

[41] Kececi N and Modarres M, "Software Development Life Cycle Model To Ensure Software Quality ", Department of Materials and Nuclear Engineering, University of Maryland, USA.

[42] Sawyer S,(2001),"Effects on intra group conflict on packaged software development team performance" ,Pennsylvania University, USA.

[43] Edward J,\&Steinke G,(2008),"Ethical Issues in Software Quality Assurance Function", communication of IIMA,VOL 8, ISSUE 1.

[44] Singh I," Effectiveness of different personalities in various roles in a software engineering team", Carnegie Mellon University,USA.

[45] Pressman R, "Software Engineering :A practitioner's approach", McGraw Hill, seventh edition.

\section{Authors Biography}

Lena khaled is an assistant professor at the Faculty of Science and Information Technology, Department of Software Engineering, Zarqa University, Jordan. Her researches are on: Architectural Design, design of E commerce systems, Component Based Development and Software Quality Assurance. 